\title{
cGMP Signaling Increases Antioxidant Gene Expression by Activating Forkhead Box 03A in the Colon Epithelium
}

\author{
Rui Wang, * Bianca N. Islam, * Allison Bridges, * Sarah K. Sharman, * Muhan Hu, * Yali Hou, * Payaningal R. Somanath, \\ Laine Venable, ${ }^{*}$ Nagendra Singh, ${ }^{*}$ Sangmi Kim, ${ }^{*}$ Subbaramiah Sridhar, ${ }^{\ddagger}$ Franz Hofmann, ${ }^{\S}$ and Darren D. Browning*
}

\begin{abstract}
From the Department of Biochemistry and Molecular Biology, * Cancer Research Center, and the Section of Gastroenterology and Hepatology, ${ }^{\ddagger}$ Department of Medicine, Augusta University, Augusta, Georgia; the Clinical and Experimental Therapeutics, ${ }^{\dagger}$ University of Georgia and Charlie Norwood VA Medical Center, Augusta, Georgia; and the Institute of Pharmacology and Toxicology, ${ }^{\S}$ Technical University of Munich, Munich, Germany
\end{abstract}

\author{
Accepted for publication \\ October 17, 2016. \\ Address correspondence to \\ Darren D. Browning, Ph.D., \\ Department of Biochemistry \\ and Molecular Biology, Geor- \\ gia Cancer Center, Augusta \\ University, 1410 Laney Walker \\ Blvd, CN 1164, Augusta, GA \\ 30912-2100. E-mail: \\ dbrowning@augusta.edu.
}

\begin{abstract}
Signaling through CGMP has therapeutic potential in the colon, where it has been implicated in the suppression of colitis and colon cancer. In this study, we tested the ability of cGMP and type 2 cGMPdependent protein kinase (PKG2) to activate forkhead box 0 (Fox0) in colon cancer cells and in the colon epithelium of mice. We show that activation of PKG2 in colon cancer cells inhibited cell proliferation, inhibited AKT, and activated Fox0. Treatment of colon explants with $8 \mathrm{Br}$-cGMP also activated Fox 0 target gene expression at both RNA and protein levels, and reduced epithelial reduction-oxidation (redox) stress. Fox03a was the most prominent isoform in the distal colon epithelium, with prominent luminal staining. Fox03a levels were reduced in $P r k g 2^{-/-}$animals, and Fox 0 target genes were unaffected by $8 \mathrm{Br}-$ cGMP challenge in vitro. Treatment of mice with the phosphodiesterase-5 inhibitor vardenafil (Levitra) mobilized Fox03a to the nucleus of luminal epithelial cells, which corresponded to increased Fox 0 target gene expression, reduced redox stress, and increased epithelial barrier integrity. Treatment of human colonic biopsy specimens with $8 \mathrm{Br}$-cGMP also activated catalase and manganese superoxide dismutase expression, indicating that this pathway is conserved in humans. Taken together, these results identify a novel signaling pathway in the colon epithelium, where Fox0 tumor suppressors could provide protection from redox stress. Moreover, this pathway is regulated by endogenous CGMP/PKG2 signaling, and can be targeted using phosphodiesterase-5 inhibitors. (Am J Pathol 2017, 187: 377-389; http://dx.doi.org/ 10.1016/j.ajpath.2016.10.016)
\end{abstract}

The epithelial lining of the intestine is an essential barrier that separates luminal contents from the underlying tissues. ${ }^{1}$ The epithelium is continuously turned over by proliferation at the crypt base, terminal differentiation, and apoptosis at the luminal surface. ${ }^{2,3}$ An imbalance in this homeostatic process can compromise the intestinal barrier, and leakage of luminal contents into the mucosal compartment promotes inflammation. $^{4-6}$ Inflammatory cytokines and reactive oxygen species (ROS) can further compromise barrier function and set the stage for inflammatory bowel disease and colorectal cancer. ${ }^{7,8}$ Oxidative stress arising from ingested chemicals and endogenous microbiota is also barrier disruptive and plays an important role in carcinogenesis in the colon. ${ }^{9-12}$ In this stressful microenvironment, the antioxidant machinery of the intestinal epithelium has an important role in preserving reduction-oxidation (redox) balance and cellular integrity.

Uroguanylin and guanylin are endogenous peptide hormones that trigger intracellular cGMP production by activating guanylyl cyclase $\mathrm{C}$ receptors $(\mathrm{GC}-\mathrm{C})$ in the intestinal epithelium. $^{13,14}$ This system is well established in the

\footnotetext{
Supported by NIH/National Cancer Institute grant R01 CA172627 (D.D.B.) and Augusta University/University of Georgia Seed grant GASGP00008 (D.D.B. and P.R.S.)

Disclosures: None declared.

Current address of R.W., Department of Surgical Oncology, University of Texas MD Anderson Cancer Center, Houston, TX.
} 
regulation of fluid and electrolyte balance, ${ }^{15}$ but has emerged more recently as fundamentally important for the maintenance of epithelial homeostasis and barrier integrity. Mice that are deficient in either guanylin or GC-C have reduced cGMP levels, an increased proliferative compartment, increased apoptosis, and reduced differentiation of secretory lineage cells in the intestine. ${ }^{16,17}$ GC-C knockout mice also exhibit a compromised epithelial barrier that is more susceptible to insult by chemicals, pathogens, and ionizing radiation. ${ }^{18-21}$ These observations suggest that GC-C/cGMP signaling is tumor suppressive in the gut, which has been supported by studies using mouse models of intestinal tumorigenesis. ${ }^{22,23}$

The mechanisms and signaling responsible for the reduced resilience of the epithelial barrier in cGMP-deficient mice are poorly understood. Type 2 cGMP-dependent protein kinase (PKG2) is the central cGMP effector in the gut epithelium that mediates fluid secretion by controlling ion channels. ${ }^{24,25}$ PKG2 knockout mice also exhibit crypt hyperplasia and increased apoptosis of the luminal epithelium, indicating that PKG2 mediates the homeostatic effects of cGMP in the colon. ${ }^{26}$ We recently demonstrated that PKG2 suppresses apoptosis in the colon epithelium, in part by increasing dual specificity protein phosphatase 10 expression, which suppresses c-Jun N-terminal kinase (JNK) activity. ${ }^{27}$ It has also been reported that cGMP can attenuate AKT signaling in the gut mucosa, but the role of PKG2 in that pathway is not known. These studies demonstrated that inhibition of AKT1 promotes mitochondrial oxidative phosphorylation and is responsible for the differentiationpromoting effects of cGMP in the colon epithelium. ${ }^{28}$ In addition, suppression of AKT by cGMP was also reported to reduce epithelial barrier permeability by increasing junctional protein expression. ${ }^{21}$ Although these observations can explain the leaky epithelial barrier in the colons of GC-C knockout mice, it remains unclear how suppression of AKT activity would confer increased epithelial resiliance and reduced apoptosis.

Forkhead box $\mathrm{O}$ (FoxO) transcription factors have important roles in coordinating environmental stressors with the regulation of cell growth and tissue homeostasis. ${ }^{29}$ There are four mammalian FoxO proteins that are widely expressed, but with differences in isoform-specific expression in various tissues. FoxO 1, 3a, and 4 are ubiquitous but are at higher levels in adipose tissue, liver, and skeletal muscle (respectively), whereas FoxO6 is predominantly found in the brain. ${ }^{30,31}$ All FoxO isoforms are phosphorylated by $\mathrm{AKT}$, which effectively inactivates them by sequestration in the cytosol. ${ }^{32}$ FoxO proteins can be activated by growth factor deprivation, and also by oxidative stress. ${ }^{33}$ Mobilization of FoxO to the nucleus can activate antioxidant and damage repair genes, metabolic genes, or genes that regulate cell cycle arrest and apoptosis. In quiescent cells, FoxO3a protects from oxidative stress, ${ }^{34}$ suggesting a protective role in the intestinal epithelium. However, despite a relatively robust literature on FoxO proteins, there is little information about their expression or function in the colon mucosa.

In the present study, we have tested the importance of PKG2 in the regulation of the AKT-FoxO signaling axis in the colon epithelium and in colon cancer cells. We show that PKG2 is necessary for AKT inhibition and activation of FoxO in colon cancer cells. We further show that FoxO3a is the prominent isoform in the colon epithelium, and that increasing cGMP levels activates FoxO target gene expression in a PKG2dependent manner. Activating cGMP signaling using the phosphodiesterase-5 (PDE5) inhibitor vardenafil increased antioxidant gene expression and reduced redox stress in the colon mucosa. Our data provide new insight into cGMP and FoxO signaling in the colon epithelium and highlight a novel application of this pathway to reduce redox stress.

\section{Materials and Methods}

\section{Cell Lines and Animals}

Colon cancer cell lines were obtained from ATCC (Manassas, $\mathrm{VA})$ and maintained in $5 \% \mathrm{CO}_{2}$ in RPMI 1640 medium containing $10 \%$ fetal bovine serum, and supplemented with 2 $\mathrm{mmol} / \mathrm{L} \mathrm{L}$-glutamine, $10 \mathrm{IU} / \mathrm{mL}$ penicillin, and $10 \mathrm{mg} / \mathrm{mL}$ streptomycin. Cells with inducible PKG2 expression have been described previously. ${ }^{26}$ The doxycycline and 8Br-cGMP were from Calbiochem (San Diego, CA). NP-40, Tween-20, and puromycin were from Sigma (St. Louis, MO). G418 was from Hyclone (Logan, UT), and all other chemicals were from Fisher Scientific (Pittsburgh, PA). Most studies were done with age-matched CD-1 mice purchased from Harlan (Prattville, AL). The type 2 PKG knockout $\left(\operatorname{Prkg}^{-/-}\right)$mouse was provided by Dr. Franz Hofmann (Technical University of Munich, Munich, Germany), with $129 \mathrm{~S} 1 / \mathrm{Sv} \times 129 \mathrm{X} 1 / \mathrm{SvJ}$ genetic background, ${ }^{25}$ and was bred and genotyped as previously described. ${ }^{26,27}$ All mouse procedures were approved by the Augusta University (Augusta, GA) Institutional Animal Care and Use Committee.

\section{Constructs, Antibodies, and Reagents}

The FoxO expression constructs and the FHRE-Luc reporter construct were purchased from Addgene (Cambridge, MA). The phosphatase and tensin homolog (PTEN) and Negative Control siRNAs were purchased from Invitrogen (Grand Island, NY). The former is a Validated Stealth RNA interference composed of a mixture of three different oligonucleotides. Antibodies used for immunoblotting recognized PKG2 (Santa Cruz, CA), $\beta$-actin (Sigma), and catalase (R\&D Systems, Minneapolis, MN). For histology, antiFoxO4 was from LSBio (Seattle, WA), and all other antibodies were purchased from Cell Signaling (Danvers, MA). The $8 \mathrm{Br}-\mathrm{cGMP}$ and the PTEN inhibitor $\mathrm{bpV}$ (phen) were from EMD Millipore (Billerica, MA). The carboxy-2' ${ }^{\prime} 7^{\prime}$-dichlorofluorescein was from Invitrogen, and the pyocyanin was from Enzo Life Sciences (Farmingdale, NY). 


\section{Phosphodiesterase Inhibitor Treatment}

Pharmaceutical-grade PDE5 inhibitor vardenafil (Levitra, Whippany, NJ) was pulverized with mortar and pestle and stored as a colloidal suspension in phosphate-buffered saline at $-80^{\circ} \mathrm{C}$. Animals were injected (i.p.) with a vehicle or with a vardenafil dose of $0.6 \mathrm{mg} / \mathrm{kg}$ at 12-hour intervals. For in vitro studies, the gut was removed, rinsed with phosphatebuffered saline, and divided into sections, and the explants were incubated under tissue culture conditions. For all studies, the mucosa was harvested from underlying tissue by scraping.

\section{Biopsy Acquisition and Processing}

The human mucosal biopsy specimens were collected from patients undergoing routine colonoscopy and were deemed normal by a board-certified pathologist. Freshly obtained tissues were immediately placed in RPMI 1640 medium on ice and transported to the laboratory within 10 minutes of accrual. Specimens were then treated with or without $8 \mathrm{Br}-\mathrm{cGMP}$ and placed in an incubator at $37^{\circ} \mathrm{C}, 5 \% \mathrm{CO}_{2}$, for 2 hours before RNA extraction. The Institutional Review Board of Augusta University approved the study protocol, and all patients consented to participate with the understanding that the results were to be published for research purposes.

\section{Reverse Transcriptase PCR}

Steady-state RNA levels were measured by semiquantitative reverse transcriptase PCR using GeneAmp PCR kits (Applied Biosystems, Foster City, CA) and primers designed using Primer Blast Software (National Center for Biotechnology
Information, Bethesda, MD; https://www.ncbi.nlm.nih.gov/ tools/primer-blast) (Table 1) and purchased from Integrated DNA Technologies (Coralville, IA). Semiquantitative reverse transcriptase PCR was used to determine the relative steadystate levels of mRNA. Total RNA was isolated using TRIzol reagent, according to manufacturer's instructions (Invitrogen), and cDNA was generated using the GeneAmp reverse transcriptase system (ThermoFisher Scientific, Waltham, MA). PCR was performed using $1 \mu \mathrm{L}$ cDNA in reactions with 0.2 U Taq (TaKara Bio Inc., Mountain View, CA), 30 cycles at $60^{\circ} \mathrm{C}$ annealing temperature.

For real-time quantitative PCR analysis of human colonic biopsy specimens, the specimens were incubated in vitro with or without $8 \mathrm{Br}$-cGMP, and the RNA was then extracted from the scraped mucosa using TRIzol reagent and PureLink RNA Mini Kit (ThermoFisher Scientific). The RNA was subsequently converted to cDNA using M-MLV reverse transcriptase (ThermoFisher Scientific). Quantitative reverse transcriptase PCR analysis of the cDNA was performed using SYBR Green PCR Master Mix (Applied Biosystems). Relative expression levels were calculated using the $2^{-\triangle \Delta C T}$ method, with $\beta$-actin $(A C T B)$ as a reference. Biopsy specimen amplifications were performed in duplicate or in triplicate wells, and melt curve analysis was done to confirm the specificity of the primers used.

\section{Fox0 Reporter Assay}

The experimental design and analysis for the luciferase reporter assay has been described previously. ${ }^{35}$ Briefly, cells were cultured in 12 -well plates, and at $80 \%$ confluence the assays were performed by transfecting triplicate wells with luciferase reporter plasmids using Lipofectamine

Table 1 Oligonucleotide Sequences Used for Reverse Transcriptase PCR

\begin{tabular}{|c|c|c|c|}
\hline Species & Gene & Forward sequence & Reverse sequence \\
\hline Human & $C A T$ & $5^{\prime}$-CGTGCTGAATGAGGAACAGA-3' & 5'-TCTTCATCCAGTGATGAGCG-3' \\
\hline qPCR human & CAT & $5^{\prime}-$ ACGGGGCCCTACTGTAATAA-3' & $5^{\prime}$-AGATGCAGCACTGGAAGGAG- $3^{\prime}$ \\
\hline Human & GADD45 & $5^{\prime}$-AAAGGATGGATAAGGTGGGG-3' & 5'-TCCCGGCAAAAACAAATAAG-3' \\
\hline Human & SOD2 & $5^{\prime}$-AATCAGGATCCACTGCAAGG-3' & 5'-AAGGCATCCCTACAAGTCCC-3' \\
\hline qPCR human & SOD2 & 5'-TAGGGCTGAGGTTTGTCCAG-3' & $5^{\prime}-$ GGAGAAGTACCAGGAGGCGT-3' \\
\hline qPCR human & PRDX3 & 5'-GACGCTCAAATGCTTGATGA-3' & 5'-GATTTCCCGAGACTACGGTG-3' \\
\hline Human & HPRT1 & $5^{\prime}$-GATGAAGAGCAAGGTTATGAC-3' & $5^{\prime}-\mathrm{ACACAGAGCAACGATATGG-3'}$ \\
\hline qPCR human & ACTB & $5^{\prime}-$ TGAAGGTGACAGCAGTCGGTTG-3' & $5^{\prime}$-GGCTTTTAGGATGGCAAGGGAC-3' \\
\hline Mouse & Cat & 5'-GGACGCTCAGCTTTTCATTC-3' & 5'-AGAAGCCCGGATTATCGTTT-3' \\
\hline Mouse & Gpx1 & $5^{\prime}$-GTGGCGGGTTCGAGCCCAATT-3' & $5^{\prime}$-GCCAGGGCCGCCTTAGGAGT-3' \\
\hline Mouse & $\operatorname{Prd} \times 3$ & $5^{\prime}-$ TCGTCAAGCACCTGAGTGTC- $3^{\prime}$ & $5^{\prime}$-CACTCGGGGAGAATTGGTTA-3' \\
\hline Mouse & Gsr & $5^{\prime}$-GCTCTGGGCCATTCGACGGG-3' & $5^{\prime}$-GAAGTCGGCCTTGGTGGCCC $-3^{\prime}$ \\
\hline Mouse & Actb & $5^{\prime}$-CTGAGAGGGAAATCGTGCGT-3' & $5^{\prime}$-AGCTCAGTAACAGTCCGCCT-3' \\
\hline
\end{tabular}

qPCR, real-time quantitative PCR. 
2000 reagent (ThermoFisher Scientific). FoxO activation was measured using FHRE-luciferase reporter plasmid that has been described previously. ${ }^{36}$ Cells were cotransfected with $0.6 \mu \mathrm{g}$ luciferase reporter per well and $0.2 \mu \mathrm{g}$ human cytomegalovirus immediate early gene promoter- $\beta$-galactosidase to control for cell number and transfection efficiency. After 16 hours, the medium was changed and cells were stimulated with $100 \mu \mathrm{mol} / \mathrm{L} 8-\mathrm{Br}-\mathrm{cGMP}$ for an additional 6 to 8 hours before enzyme assay.

\section{Immunohistochemistry and Western Blotting}

Cell and tissue lysates were prepared and separated on PAGE gels, as described previously. ${ }^{26}$ Quantitation of Western blots was performed on low-exposure scans using ImageJ software version 1.48 (NIH, Bethesda, MD; http:// imagej.nih.gov/ij). ${ }^{37}$ Data from different experiments were normalized to control (untreated) lanes. Animal tissues were processed for histological analysis, as described previously, ${ }^{26}$ and probed using antibodies to FoxO isoforms using the same antibodies as for immunoblotting. Histological interpretation and analysis was done independently by two individuals who were blinded to treatments (A.B. and R.W.). The intensity of FoxO staining was measured using ImageJ software relative to background, for at least 10 fields containing at least 10 crypts per field for each animal.

\section{Cell Proliferation Assays}

Cell growth was measured by seeding 12 -well plates with $10^{4}$ cells per well in triplicate, and after 24 hours (day 0 ) the medium was changed. Viable cell numbers were measured on days 1 and 3 by mixing equal volumes of trypan blue with cell suspension, and counting in a TC20 cell counter (Biorad, Hercules, CA). For siRNA knockdown experiments, the cells were transfected with siRNA in the 12-well plates on day 0 .

\section{cGMP and ROS Measurements}

The cGMP level in mouse colon mucosa was quantitated, as previously described, ${ }^{27}$ using a cGMP EIA Kit (Cayman, Ann Arbor, MI) and standardized to protein measured by the Bradford assay (BioRad). ROS in colon explants were measured by incubating freshly dissected mouse colons in tissue-culture conditions. After various treatments, carboxy- $2^{\prime}, 7^{\prime}$-di-chlorofluorescein $(5 \mu \mathrm{mol} / \mathrm{L})$ was added, and after 30 minutes, the tissue was rinsed briefly in phosphate-buffered saline, and the epithelium was removed by scraping and transferred to a black 96-well dish for measuring fluorescein fluorescence in a Tecan Ultra plate reader (Tecan US Inc., Morrisville, NC).

\section{Barrier Permeability Assay}

C57/BL6 mice (The Jackson Laboratory, Bar Harbor, ME) were randomized into three groups: untreated, dextran sulfate sodium (DSS)-vehicle, and DSS-vardenafil. The latter two groups were treated with $2 \%$ DSS in the drinking water for 5 days. Administration of vardenafil or vehicle to the DSS-treated mice was done by i.p. injection the night before and repeated 1 hour before fluorescein isothiocyanate-dextran administration. To measure barrier permeability, mice were gavaged with $100 \mu \mathrm{L}$ of fluorescein isothiocyanate-dextran $(100 \mathrm{mg} / \mathrm{mL} ; 4 \mathrm{kD}$; Sigma-Aldrich, St. Louis, MO) after an overnight fast. Blood was collected from the submandibular vein after 90 minutes, and serum was analyzed by fluorimetry to determine the fluorescein isothiocyanate-dextran concentration.

\section{Statistical Analysis}

All quantitative data were reproduced in at least three independent experiments with multiple measures in each replicate. The resulting data were expressed as means, with error bars indicating SEM, and analyzed using a two-tailed $t$-test. The real-time quantitative PCR data were analyzed using the $U$-test (one sided). Each untreated biopsy specimen served as its own internal control for the treated specimen. Two means were considered to be statistically significant if $P<0.05$. Statistical analyses were completed in GraphPad Prism software version 7.01 (GraphPad Software, La Jolla, CA).

\section{Results}

PKG2 Inhibits AKT Signaling and Proliferation in Colon Cancer Cells

A large body of evidence supports the idea that increasing cGMP levels has antiproliferative effects in colon cancer cell lines. Several of these studies have suggested that inhibition of $\beta$-catenin/T-cell factor by type 1 PKG (PKG1) is a possible growth-inhibitory mechanism in colon cancer cells. ${ }^{38}$ More recently, type 2 PKG (PKG2) has also been reported to inhibit proliferation in gastric cancer cells lines by a mechanism involving inhibition of extracellular signal regulated kinase (ERK) and AKT signaling pathways. ${ }^{29,39,40}$ To determine whether PKG2 can also inhibit these pathways in colon cancer cells, we made use of cell lines made inducible for PKG2 expression that have been characterized previously. ${ }^{26}$ Activation of PKG2 in LS174T colon cancer cells inhibited growth without affecting apoptosis (Figure 1, A and B). Surprisingly, in the absence of PKG2 expression, treatment of the LS174T cells with membrane-permeable 8Br-cGMP increased phosphorylation of both ERK44/42 and mitogen activated protein kinase, ERK kinase (MEK)1/2 (Figure 1, C and D) but did not affect the phosphorylation status of AKT (Ser473) or its substrate FoxO1 (Ser256) (Figure 1, E and F). In cells that were induced to express PKG2, the 8Br-cGMP did not affect the MEK/ERK pathway, but dramatically reduced phospho-AKT and phospho-FoxO1 levels relative to untreated controls. PKG2 expression by itself slightly 


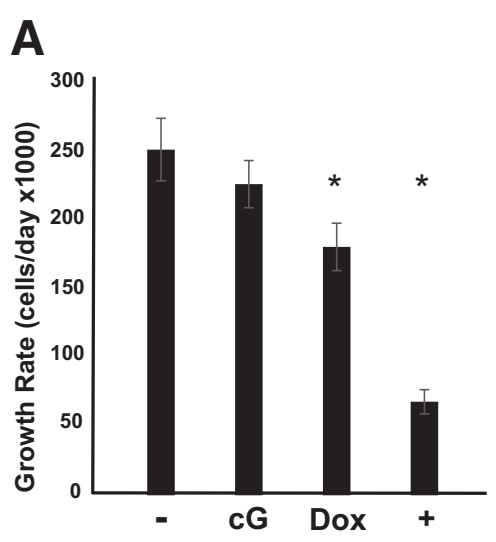

D

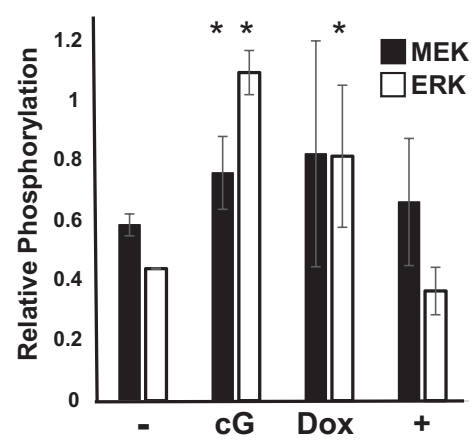

B

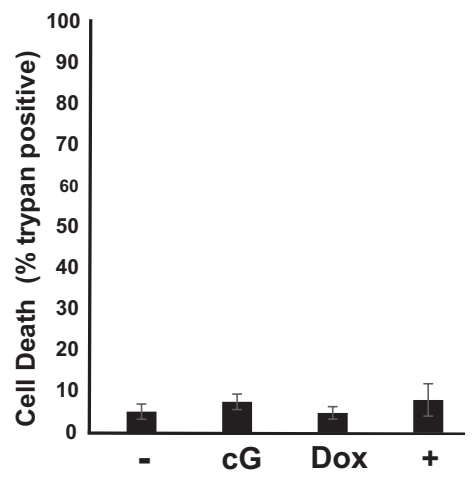

$\mathbf{E}$

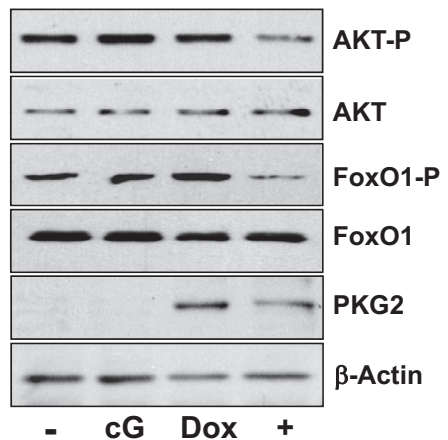

C

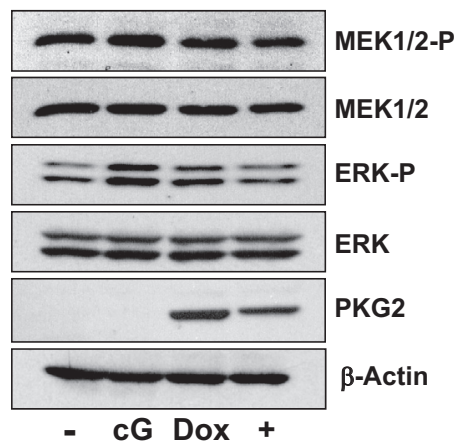

$\mathbf{F}$

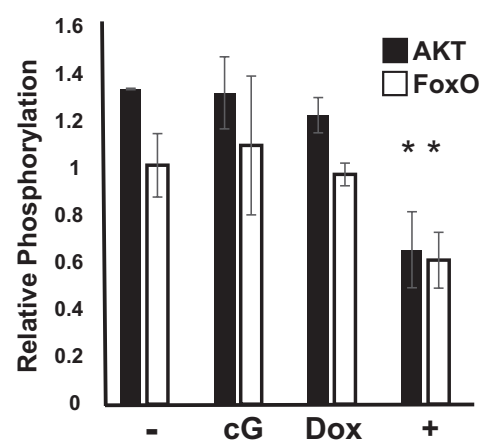

Figure 1 Inhibition of colon cancer cell growth by PKG2 is associated with reduced AKT activity. A: The proliferation of LS174T cells with inducible expression of PKG2 was measured. Cells were either untreated (-) or treated with inducer doxycycline and PKG2-activator 8Br-cGMP (+) for 3 days. B: The effect of cGMP/PKG2 on death of LS174T cells was measured as above using trypan blue exclusion. C and E: The effect of cGMP and PKG2 on MEK/extracellular signal regulated kinase (ERK) activity (C) and AKT/Fox0 signaling pathways (E) was measured by Western blotting. Untreated control cells ( - ), those treated with $8 \mathrm{Br}$-cGMP alone (cG), and those treated with doxycycline (Dox) to induce PKG2 expression, or both $\mathrm{cG}$ and Dox (+) were harvested after 24 hours. $\beta$-Actin is shown as a loading control. Western blot data were quantitated to show relative phosphorylation of MEK/ERK (D) and AKT/Fox01 (F). Data are expressed as means \pm SD $(\mathbf{A}, \mathbf{B}, \mathbf{D}$, and $\mathbf{F}) . n=3(\mathbf{A}$ and $\mathbf{B}) ; n=4(\mathbf{D}$ and $\mathbf{F}) .{ }^{*} P<0.05$ versus untreated. MEK, mitogen activated protein kinase, ERK kinase.

increased phospho-ERK levels, but blocked the increase resulting from 8Br-cGMP. Similar results were observed using HT29 colon cancer cells (Supplemental Figure S1). To better understand the mechanism underlying inhibition of the AKT pathway by PKG2, the levels of upstream signaling components were also examined. Activation of PKG2 led to a small reduction in phospho-3phosphoinositide-dependent protein kinase-1 (Ser241) levels, suggesting that the effect of PKG2 is further upstream in the AKT pathway (Figure 2A). Interestingly, induction of PKG2 expression caused an increase in the total level of PTEN protein, but treatment of the cells with $8 \mathrm{Br}-$ cGMP reduced PTEN levels. However, the phosphorylation status of PTEN was not notably changed. Reducing the level or activity of PTEN using siRNA knockdown or treatment with the PTEN inhibitor bpV (respectively) blocked the ability of PKG2 to suppress AKT (Figure 2, B and C). To determine the significance of AKT inhibition by PKG2, we tested the effect of PTEN knockdown on cell growth. Knockdown of PTEN was found to reduce cell proliferation compared to nontargeting siRNA (Figure 2D). However, PTEN knockdown completely blocked the inhibitory effects of PKG2 activation of cell proliferation in these cells. Taken together, these results suggest that PKG2 inhibits AKT signaling and that this might contribute to the inhibition on cell proliferation downstream of cGMP in colon cancer cells.

\section{Activation of Fox0 by cGMP Signaling}

It is well established that AKT regulates a plethora of signaling pathways that collectively promote cell survival and proliferation. An important target of AKT is the FoxO transcription factors, which are inactivated on phosphorylation by $\mathrm{AKT}^{32}$ In the absence of AKT activity, FoxO proteins move to the nucleus, where they can activate the expression of antioxidant, cell-cycle inhibitory, and proapoptotic genes. ${ }^{28}$ The diversity of FoxO target genes indicates the importance of these proteins as tumor suppressors, and for protection against ROS. Because the present studies demonstrated that cGMP/PKG2 can inhibit AKT signaling in colon cancer cells, we sought to determine whether FoxO might be activated. Initial studies used a luciferase reporter construct driven by consensus FoxO binding sites, which could be activated 


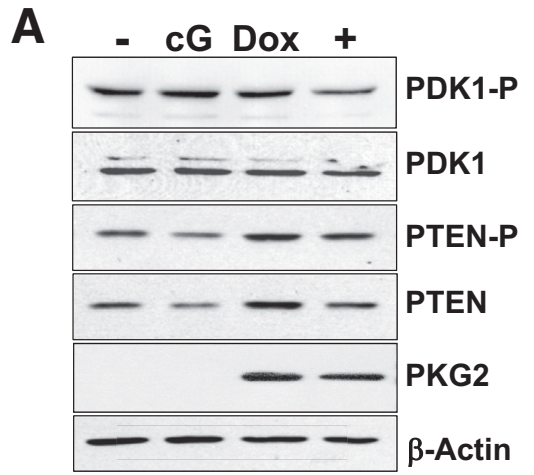

C

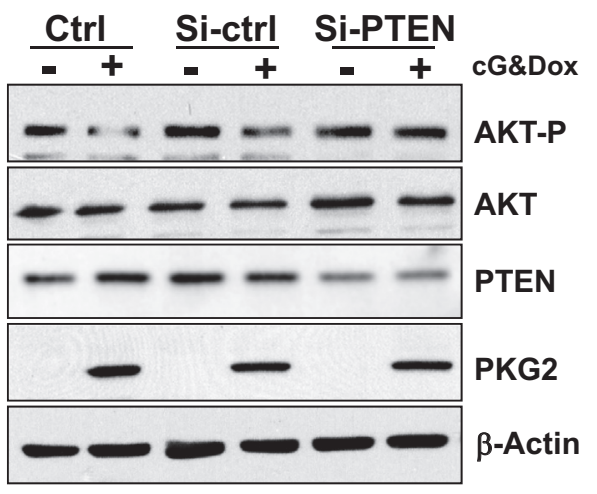

B

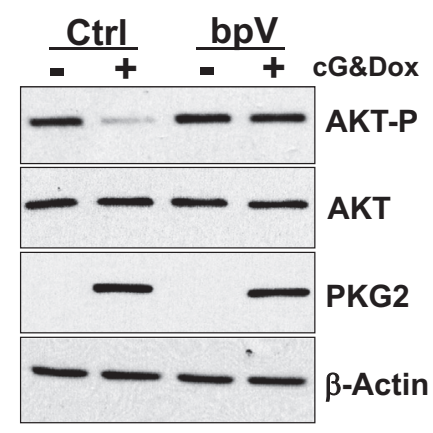

D

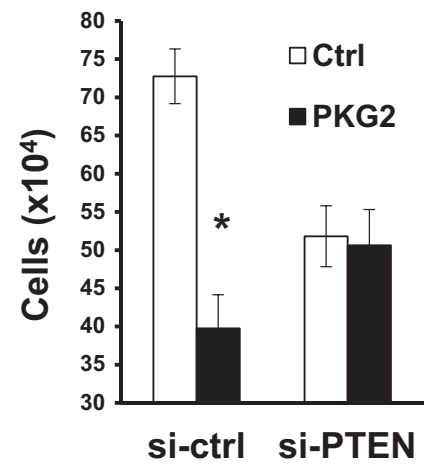

Figure 2 Phosphatase and tensin homolog (PTEN) is essential for the inhibition of AKT and cell proliferation by PKG2. A: LS174T colon cancer cells were either untreated $(-)$ or treated with the PKG2activator 8Br-cGMP (cG), the PKG2-inducer doxycycline (Dox), or both $\mathrm{CG}$ and Dox (+). After 24 hours, cell extracts were analyzed for immunoblotting for phospho-3-phosphoinositide-dependent protein kinase-1 (PDK1) and phospho-PTEN. Total PDK1 and PTEN are also shown. B: Cells were either untreated $(-)$ or treated with doxycycline and $8 \mathrm{Br}-\mathrm{cGMP}(+)$ in the presence (bpV) or absence [control (Ctrl)] of the PTEN inhibitor bpV(phen). After 15 hours, the phospho-AKT levels were measured by immunoblotting. C: Cells were untransfected (Ctrl) or transfected with nontargeting (si-ctrl) or PTENspecific (si-PTEN) siRNAs. After 24 hours, cells were treated overnight with cGMP and doxycycline, and phospho-AKT and PTEN levels were measured by immunoblotting. D: The effect of nontargeting (si-ctrl) or PTEN-specific (si-PTEN) siRNAs on the ability of PKG2 to inhibit cell proliferation was measured by cell counting. All Western blots were reprobed for $\beta$-actin as loading control and PKG2 to confirm expression. Growth data are expressed as means \pm SEM (D). $n=3$ (A-D). ${ }^{*} P<0.05$ versus ctrl. threefold by overexpression of FoxO1, FoxO3a, or FoxO4 in LS174T cells (Figure 3A). Treatment of cells with 8Br-cGMP alone did not affect FoxO reporter activity, but in cells expressing PKG2 it caused a twofold increase relative to untreated controls (Figure 3B). Consistent with the idea that PKG2 can activate endogenous FoxO activity in LS174T cells, treatment of PKG2-expressing cells with 8Br-cGMP increased the steady-state levels of several established FoxO target genes (Figure 3C). Similar results were observed using HT29 colon cancer cells (Supplemental Figure S1).

The potential protective and tumor-suppressive effects of FoxO signaling prompted us to determine whether cGMP could also activate this pathway in the normal colon epithelium of mice. This was tested by treating mouse colon explants with $8 \mathrm{Br}-\mathrm{cGMP}$ in vitro and measuring FoxO target gene expression in the mucosa. These experiments showed that $8 \mathrm{Br}$-cGMP exposure increased the expression of several classic FoxO-dependent antioxidant genes at both the mRNA and protein levels in mucosa from both proximal and distal regions of the colon (Figure 4, A and B). Antioxidant gene expression typically increases in response to ROS, which can activate several defensive signaling pathways, including FoxO and nuclear factor erythroid 2 related factor $2 .{ }^{33,41}$ To determine whether increasing cGMP affects redox stress in the colon mucosa, the effect of $8 \mathrm{Br}-\mathrm{cGMP}$ on carboxy- $2^{\prime}, 7^{\prime}$ di-chlorofluorescein fluorescence in colon explants was measured. These studies showed that the redox stress in the mucosa of untreated colon explants was higher than in those treated with 8Br-cGMP (Figure 4C), which indicates that
cGMP activates antioxidant gene expression in the colon mucosa in an ROS-independent manner. In support of this, treatment with pyocyanin, which is an intracellular ROS inducer, caused a significant increase in redox stress in the colon explants that was blocked by cotreatment with $8 \mathrm{Br}-$ cGMP (Figure 4C).

\section{Fox0 Expression in the Colon Mucosa}

Despite the established protective role of FoxO proteins and their targets genes in many tissues, they have not previously been examined in the gastrointestinal tract. The data presented above demonstrate FoxO activation by cGMPdependent signaling pathways in the colon mucosa, but it is not clear which of the FoxO proteins is affected by cGMP. To determine which FoxO isoforms are present in the colon epithelium, freshly isolated mucosa from the mouse proximal and distal colon was examined by immunoblotting for the most prevalent isoforms. It was found that FoxO1, 3, and 4 were all present in the proximal colon, but, although FoxO1 and 4 levels decreased in the distal colon, FoxO3a expression increased dramatically (Figure 5A). Immunohistochemical analysis showed that the different FoxO isoforms localized to different compartments, although all of them were expressed in the muscular plexus (Figure 5B). Staining the colon tissues with isotype-matched antibody (Vector Laboratories, Burlingame, CA) produced little to no staining when used at similar concentrations. FoxO1 predominantly stained lymphocytes and lymphoid aggregates 
A

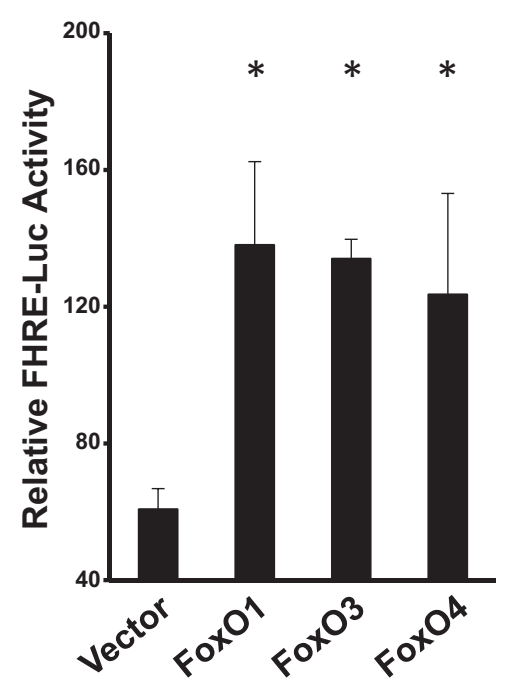

B

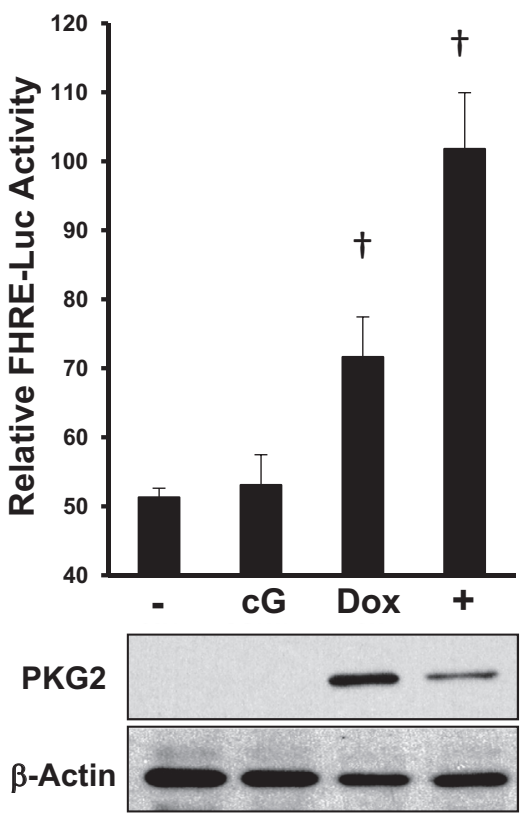

C $\mathrm{cGMP}+\mathrm{Dox}$

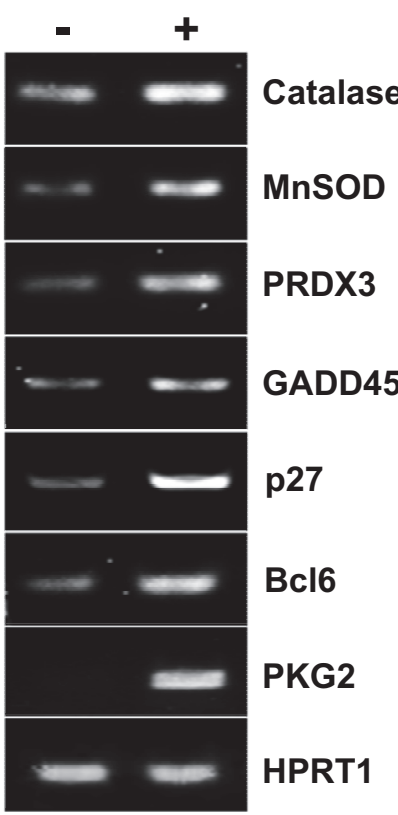

Figure 3 PKG2 activates Fox0 in colon cancer cells. LS174T colon cancer cells were transiently cotransfected with a Forkhead-responsive element (FHRE)driven luciferase reporter construct and either empty vector (Vector) or expression vectors encoding Fox01, 3, and 4 (as indicated). A: Cells were harvested, and the relative luciferase activity was determined. B: The effect of cGMP and PKG2 on FHRE-luciferase activity was determined by comparing activity in untreated cells $(-)$ to those incubated with 8Br-cGMP $(\mathrm{cG})$, doxycycline inducer (Dox), or both $(+)$. C: The effect of PKG2 on endogenous Fox0 target gene expression in LS174T cells was determined by reverse transcriptase PCR. Gels are representative of at least three experiments. Quantitative data are expressed as means \pm SEM (A and $\mathbf{B}) . n=3(\mathbf{A}-\mathbf{C}) .{ }^{*} P<0.05$ versus vector; ${ }^{\dagger} P<0.05$ versus untreated cells. GADD, growth arrest and DNA damage; HPRT, hypoxanthine phosphoribosyltranferase; MnSOD, manganese superoxide dismutase; PRDX, peroxiredoxin.

(data not shown) in both proximal and distal regions, but did not significantly stain the epithelium. In contrast, FoxO3a was present in the luminal epithelium in both proximal and distal colon, but was variable, with patches of low expression. The subcellular expression of FoxO3a was also nonuniform across the colon epithelium, because it was mostly cytosolic but exhibited patches of nuclear staining. FoxO4 was present in both luminal epithelium and further down in the crypt in the proximal colon, but in the distal colon, nuclear staining was more prominent in the crypts.

To determine whether PKG2 has a role in FoxO expression or activity in the colon mucosa, FoxO target
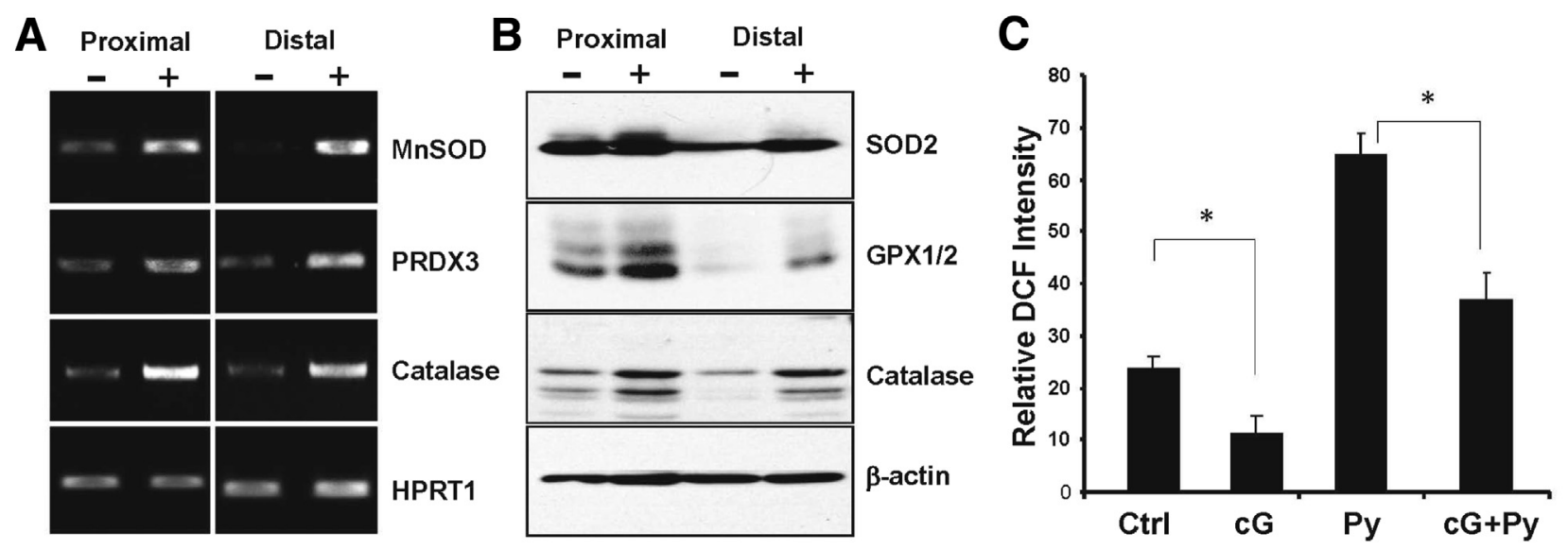

Figure 4 CGMP activates antioxidant gene expression in the colon mucosa. Mouse colons were dissected into proximal and distal regions and treated in vitro with $8 \mathrm{Br}-\mathrm{cGMP}$ for 2 hours. The mucosa was harvested and processed for analysis of antioxidant genes by reverse transcriptase PCR using HPRT1 as loading control (A) and immunoblotting using $\beta$-actin as loading control (B). C: Relative oxidative stress was measured by $2^{\prime}, 7^{\prime}$-dichlorodihydrofluorescein diacetate (DCF) fluorescence in mucosa from colons treated in vitro with vehicle [control (Ctrl)], 8Br-cGMP (cG), the reactive oxygen species inducer pyocyanin $(\mathrm{Py})$, or both $(\mathrm{CG}+\mathrm{Py})$. Experiments were performed in triplicate. Results expressed are means $\pm \mathrm{SEM}(\mathbf{C}) . n=3(\mathbf{A}-\mathbf{C})$. ${ }^{*} P<0.05 . \mathrm{GPX}, \mathrm{glutathione}$ peroxidase; HPRT, hypoxanthine phosphoribosyltranferase; MnSOD, manganese superoxide dismutase; PRDX, peroxiredoxin. 
A

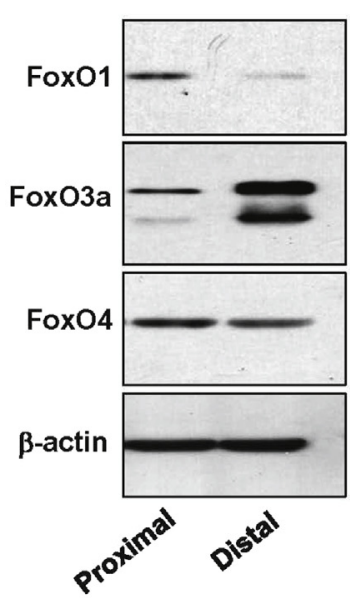

B

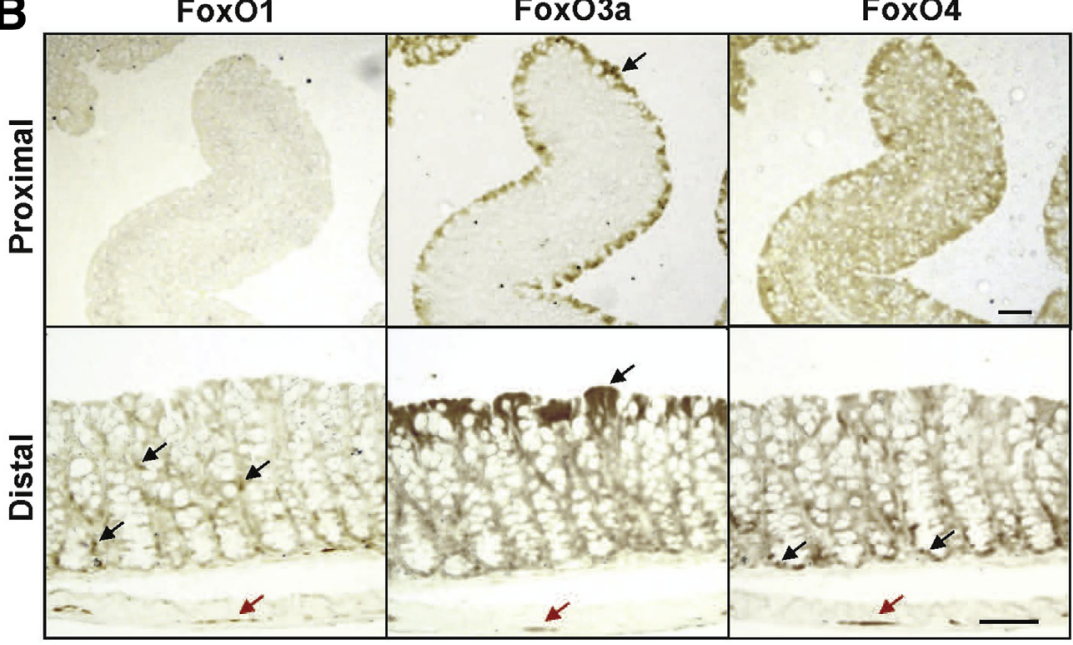

Figure 5 Expression of Fox 0 isoforms in the colon. The expression of different Fox 0 protein isoforms was measured in the proximal and distal colons by Western blotting (A) and immunohistochemistry (B). The black arrows in the bottom panel for Fox01 show leukocytes in the lamina propria. The black arrows in the top and bottom panels for Fox03a indicate intense staining of luminal epithelia. The black arrows in the bottom panel for Fox04 indicate staining in the crypts. The red arrows indicate Fox0 staining in the muscular plexus. $n \geq 3$ animals (A and $\mathbf{B}$ ). Scale bars $=50 \mu \mathrm{m}$ (B).

gene expression was measured in $\mathrm{Prkg} 2^{-1-}$ and compared to that of wild-type siblings. The mRNA levels of many FoxO target genes were reduced in the colons of $P r k g 2^{-1-}$ (Figure 6A), and were unresponsive to treatment with 8Br-cGMP (Figure 6B). This deficiency in FoxO target gene expression was associated with reduced levels of FoxO3a protein expression (Figure 6C), whereas FoxO4 was similar to wild-type animals (data not shown).

\section{Activation of Fox03a by cGMP in the Colon Epithelium}

The ability of $8 \mathrm{Br}$-cGMP to activate FoxO in the colon epithelium in vitro prompted us to determine whether cGMP has a similar effect in vivo. To test this idea, mice were treated with the PDE5 inhibitor, vardenafil, by i.p. injection, which increased mucosal cGMP levels (Figure 7A). Between 8 and 24 hours after administration of vardenafil, there was an increase in both staining intensity and in nuclear localization of FoxO3a at the epithelial border in the colon (Figure 7, B and C). This effect was not observed for either FoxO1 or FoxO4 (data not shown). In association with the altered staining pattern of FoxO3a after vardenafil treatment, there was increased expression of several FoxO target genes in the colon mucosa (Figure 7D). To determine the effect of the increased antioxidant gene expression, redox stress was measured by incubating freshly isolated colons from vardenafil-treated mice with carboxy-2' $7^{\prime}$-di-chlorofluorescein. Fluorescence of the scraped mucosa showed that mice treated with vardenafil had significantly lower redox stress relative to untreated controls (Figure 7E). Redox stress

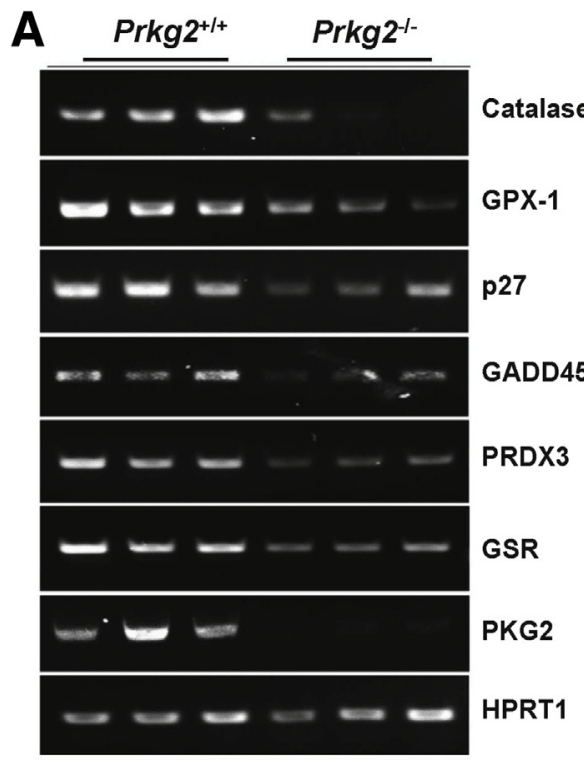

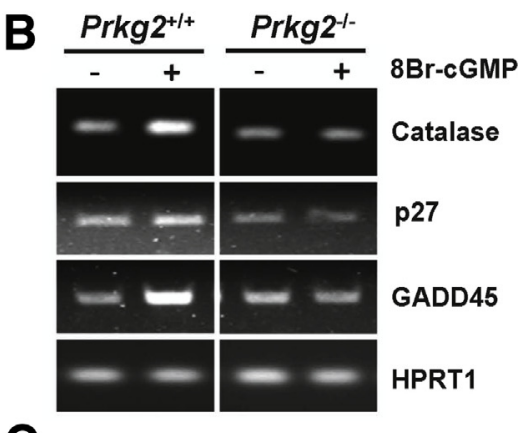

C

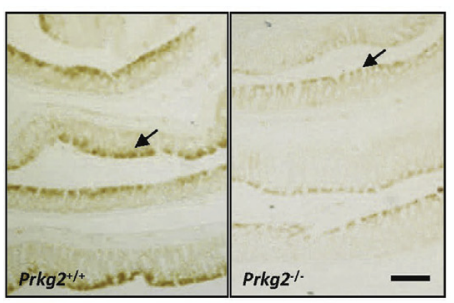

Figure 6 PKG2-deficient mice exhibit reduced Fox0 activity in the colon mucosa. Fox0 target gene expression in the colon mucosa of wild-type $\left(\right.$ Prkg2 $\left.2^{+/+}\right)$and PKG2 knockout $\left(\right.$Prkg2 $\left.^{-/-}\right)$mice was measured by reverse transcriptase PCR in freshly isolated colon (A) and in explants treated with $8 \mathrm{Br}-\mathrm{cGMP}$ for 2 hours in vitro (B). C: HPRT1 is a loading control. The expression of Fox03a in the colons of wild-type and PKG2 knockout mice was assessed by immunohistochemistry. The arrows indicate Fox03a staining of the luminal epithelium. $n \geq 3$ animals (A-C). Scale bar $=100 \mu \mathrm{m}$ (C). GADD, growth arrest and DNA damage; GPX, glutathione peroxidase; GSR, glutathione disulfide reductase; HPRT, hypoxanthine phosphoribosyltranferase; PRDX, peroxiredoxin. 

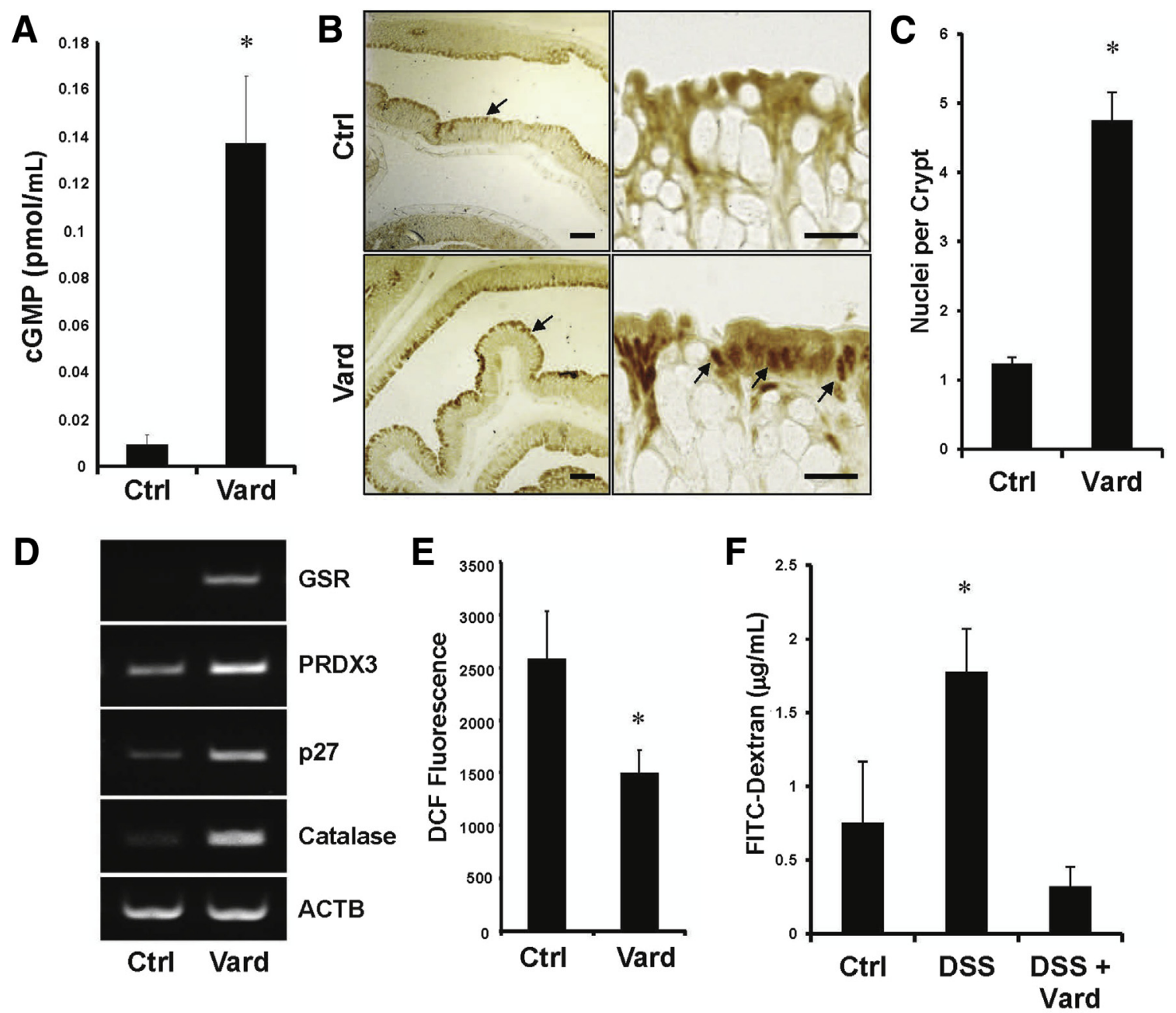

Figure 7 Vardenafil treatment activates Fox03a and reduces reduction-oxidation (redox) stress in the colon mucosa. Mice were either untreated [control (Ctrl)] or treated with the phosphodiesterase-5 inhibitor vardenafil by i.p. injection (Vard). A: After 5 hours, the cGMP levels in the colon mucosa were measured by enzyme-linked immunosorbent assay. B: After 15 hours, colons were processed for Fox03a staining by immunohistochemistry. The right column shows higher magnification of representative luminal epithelium shown to be intensely stained in the left column (arrows). The arrows in the bottom right panel indicate prominent nuclear staining for Fox03a. C: Fox03a-positive nuclei per crypt were quantitated. D: The expression of Fox0 target genes in the colons 24 hours after vardenafil treatment was assessed by reverse transcriptase PCR. E: Redox stress in the scraped colon mucosa was measured using carboxy$2^{\prime}, 7^{\prime}$-di-chlorofluorescein (DCF) fluorescence. F: The effect of acute vardenafil treatment on intestinal barrier function was assessed by permeability of fluorescein isothiocyanate (FITC) - dextran in untreated (Ctrl) and dextran sulfate sodium (DSS)-treated mice. Error bars indicate SEM (A, C, B, and F). $n>3$ (A and $\mathbf{D}-\mathbf{F}) ; n=3$ (B and $\mathbf{C})$. ${ }^{*} P<0.05$ versus ctrl. Scale bars: $100 \mu \mathrm{m}$ (B, left column); $20 \mu \mathrm{m}$ (B, right column). ACTB, beta actin; GSR, glutathione disulfide reductase; PRDX, peroxiredoxin.

can destabilize tight junctions and promote apoptosis, ultimately compromising barrier function and setting the stage for inflammatory bowel disease. ${ }^{7,8}$ We tested the ability of the cGMP/FoxO pathway to augment the epithelial barrier that had been compromised by treatment with DSS (Figure 7F). An acute dose of vardenafil (15 hours) was able to reduce the barrier permeability in this model to the level of control animals that had not received any DSS.

To determine the relevance of our observations in mice to humans, biopsy specimens of normal descending colon epithelium were obtained from routine colonoscopies. Similar to the mouse, FoxO3a was similarly expressed in the luminal epithelium with patches of nuclear staining, but in addition, leukocytes in the lamina propria also stained (Figure 8A). In addition, treatment of the biopsy specimens with 8Br-cGMP for 2 hours led to activation of FoxO-dependent antioxidant genes $(P<0.05$ for catalase and manganese superoxide dismutase) relative to untreated specimens (Figure $8 \mathrm{~B}$ ).

\section{Discussion}

There is a large body of evidence from independent laboratories demonstrating that the cGMP signaling axis has a barrier-protective role in the gastrointestinal tract, but the underlying mechanism(s) are poorly understood. In this study, we found that increasing cGMP in the colon epithelium activated FoxO3a and up-regulated antioxidant gene 

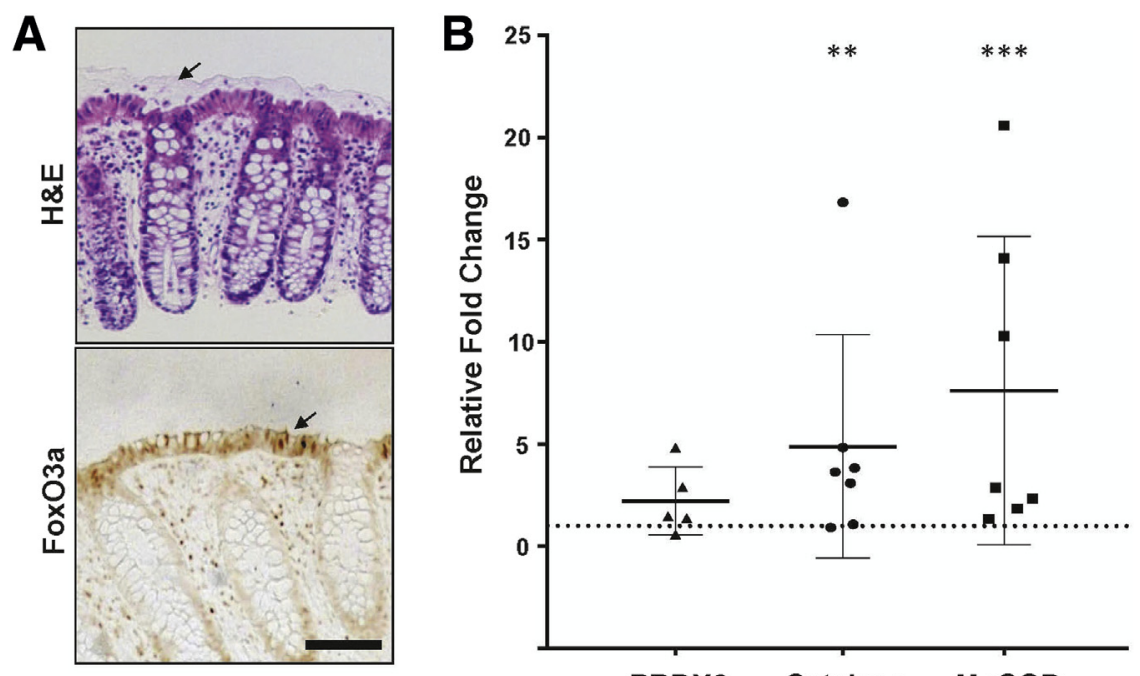

PRDX3
Catalase
MnSOD
Figure 8 Activation of Fox0 target genes by cGMP in human colon epithelium. A: Biopsy specimens from human descending colon were processed for hematoxylin and eosin (H\&E) and immunostaining for Fox03a. The arrow in the top panel highlights the intact inner mucus layer in the biopsy specimens. The arrow in the bottom panel indicates intense staining of the luminal epithelium with some nuclear localization. B: Human colonic biopsy specimens were treated with $8 \mathrm{Br}$-CGMP or vehicle for 2 hours in vitro and subjected to real-time quantitative PCR analysis of Fox0-regulated antioxidant genes. $n=$ specimens examined (A). Data are expressed as means \pm SD (B). ${ }^{* *} P<0.01,{ }^{* * *} P<0.001$ versus untreated. Scale bar $=50 \mu \mathrm{m}(\mathbf{A})$. MnSOD, manganese superoxide dismutase; PRDX, peroxiredoxin. expression to protect against redox stress and barrier dysfunction. We further showed that this pathway is mediated by PKG2, which can be activated by systemic treatment with PDE5 inhibitors.

Inhibition of AKT activity by cGMP has previously been reported to occur in the colon epithelium and in colon cancer cell lines. ${ }^{29}$ The results shown herein extend our understanding of this phenomenon by demonstrating that PKG2 mediates AKT inhibition downstream of cGMP in this pathway. Independent work has shown that PKG2 also suppresses AKT in gastric cancer cell lines, where the mechanism was suggested to occur at the level of receptortyrosine kinases because ERK was also inhibited. ${ }^{42-44}$ Our results show that in colon cancer cells that do not express PKG2, cGMP actually increased the MEK/ERK pathway but did not affect AKT signaling. However, in PKG2expressing colon cancer cells, the cGMP did not significantly affect phospho-ERK levels but dramatically reduced phospho-AKT. These results indicate that the ERK and AKT pathways are regulated differently by cGMP in colon cancer cells, and the mechanism is likely to be more complex than inhibition at the receptor level. We show herein that suppression of AKT signaling by cGMP/PKG2 occurs upstream, because phospho-3-phosphoinositide-dependent protein kinase-1 levels were reduced. Regulation of PTEN by cGMP/PKG2 signaling is likely because the total PTEN levels were affected by PKG2 expression and activation. These results are consistent with a previous study in HCT116 colon cancer cells, ${ }^{29}$ but the precise relationship between PKG2 and PTEN has yet to be elucidated. PTEN activity plays an important role downstream of PKG2 because knockdown of PTEN expression blocked the inhibitory effect of PKG2 on phospho-AKT in colon cancer cells. Knockdown of PTEN with specific siRNA also blocked the ability of PKG2 to inhibit colon cancer cell growth. This is the first evidence for the importance of AKT in the suppression of colon cancer cell growth by PKG2 and lends mechanistic support to the tumor-suppressor effects of
cGMP signaling in the gastrointestinal tract. The activity of AKT increases during progression of colorectal tumors, where it has the important role of keeping the proapoptotic and antiproliferative effects of FoxO in check. ${ }^{45}$ Aberrant FoxO activation can inhibit colon cancer cell proliferation by up-regulating cell-cycle inhibitory genes and by titrating $\beta$-catenin from T-cell factor. ${ }^{46}$ Indeed, we have previously reported that ectopic PKG1 can inhibit colon cancer cell growth by activating FoxO4. ${ }^{36}$ FoxO4 activation by PKG1 is mediated by JNK, which paradoxically was recently reported to be inhibited by PKG2. ${ }^{27}$ Herein, we demonstrate, for the first time, that PKG2 can also activate FoxO in colon cancer cells, and by an alternative mechanism involving inhibition of AKT. The inhibition of JNK by PKG2 signaling would be expected to inhibit FoxO4 activation in the colon epithelium, and might explain the apparent selectivity of cGMP for FoxO3a in vivo.

The ability of cGMP to suppress AKT activity is not limited to cancer cells, because previous studies have shown that the regulation of AKT by the guanylin/GC-C signaling axis promotes barrier function and suppresses tumorigenesis in the mouse colon. ${ }^{21,29}$ Knockout mice that are deficient in cGMP signaling exhibit aberrant AKT activity in the colon mucosa that coincides with elevated epithelial proliferation within crypts. ${ }^{21,22}$ Because AKT is an established promoter of proliferation and survival, this pathway may directly contribute to crypt hyperplasia in these knockout mice. However, it is not clear how aberrant AKT activity would increase the epithelial apoptosis and barrier dysfunction that are also observed in these animals. ${ }^{17,19,26}$ Extrinsic and intrinsic ROS are prominent in the colon epithelium, and can destabilize tight junctions to promote barrier dysfunction. ${ }^{47}$ We hypothesized that the protective effects of cGMP in the colon epithelium might be mediated by the activation of FoxO, because these transcription factors are important regulators of antioxidant gene expression. The present study is the first to characterize FoxO expression in the gut, and our results show that FoxO3a is the most prominent isoform, with 
a striking localization in the luminal border epithelium. FoxO4 was also present at the luminal border, but in contrast to FoxO3a, it also extended down into the crypts. This pattern of FoxO isoform expression is likely because of the specific targeting of FoxO3a for proteasomal degradation in proliferating cells, such as those residing deeper in the colonic crypts. ${ }^{48}$ Because JNK is a specific activator of FoxO4, the nuclear localization of FoxO4 in the crypts is likely because of higher levels of active JNK in that compartment. ${ }^{27,49}$ The function of FoxO4 in the crypt epithelium is not known, but it may have a role in restitution because knockout animals are more sensitive to epithelial damage. ${ }^{50}$ However, specific conclusions about the function of epithelial FoxO4 are complicated by the increased inflammatory activities of FoxO4-deficient leukocytes in these animals. Our results also showed that FoxO1 is undetectable in colonocytes, but was prominent in leukocytes in the lamina propria, and in neuronal tissue in the submucosa. These observations are consistent with a large body of evidence supporting important roles for FoxO1 in the regulation of leukocyte and neuronal development and function. ${ }^{51,52}$

FoxO transcription factors are associated with several classes of targets, including cell cycle regulatory, proapoptotic, metabolic, and antioxidant genes. Because PDE5 inhibition reduces apoptosis at the luminal border and augments barrier function, it is unlikely that these genes serve an important role. ${ }^{27} \mathrm{We}$ did observe increased $\mathrm{p} 27^{k i p}$ and GADD (growth arrest and DNA damage) 45 expression, suggesting the possibility that FoxO activation might promote cell cycle withdrawal and differentiation, which occurs downstream of cGMP/PKG2 signaling. ${ }^{26,27}$ The increased expression of these two antiproliferation FoxO targets could also contribute to antineoplastic and antigenotoxic effects of cGMP signaling, which have been reported previously. ${ }^{21,53,54}$ FoxO3a could therefore serve many functions in the differentiated colon epithelium, but we demonstrated herein that it can protect these cells from oxidative stress, as has been described recently for quiescent cells. $^{33}$ FoxO expression at the luminal border would therefore augment epithelial barrier resiliance to the destructive effects of ROS that are known to be generated by commensal bacteria. ${ }^{9-11}$ Although FoxO4 might also serve a protective role in the colon epithelium, only FoxO3a was activated in response to increasing cGMP with vardenafil. It has been suggested that by suppressing AKT in the colon epithelium, cGMP shifts metabolism away from glycolysis in favor of increased mitochondrial biogenesis and oxidative phosphorylation. ${ }^{38}$ This would be expected to facilitate the utilization of short chain fatty acids generated by commensal bacteria, which are the primary energy source of colonocytes. ${ }^{55}$ However, this would also increase redox stress, particularly at the luminal border, where oxygen levels are limited. ${ }^{56}$ It was shown herein that increasing cGMP in the colon epithelium caused activation of FoxO3adependent antioxidant gene expression, and protected against pyocyanin-induced intrinsic superoxide generation.
The protection from redox stress conferred by FoxO3a is not only because of activation of antioxidant gene expression, but also because of the control of mitochondrial function by antagonizing cMyc. ${ }^{57,58}$ It is possible that short-term FoxO activation favors protective antioxidant gene expression, but more prolonged ROS challenge might lead to reduced mitochondrial function as a feedback mechanism at the cost of butyrate utilization. The contention that cGMP promotes mitochondrial biogenesis, as reported previously, ${ }^{38}$ is ostensibly at odds with FoxO suppressing cMyc function. However, it is possible that the increased mitochondrial biogenesis observed previously in response to cGMP could be indirect, and associated with increased differentiation rather than a direct effect on the mitochondria. It is well established that PKG2 controls electrolyte and fluid in the small intestine, but this function is not present in the colon, where its role is not understood. ${ }^{59}$ Results shown herein indicate that protecting the epithelial barrier from redox stress could be the main function of PKG2 in the colon, which is subjected to more oxidative damage arising from the anaerobic environment and a more robust microbiota. The inhibition of cGMP degradation by vardenafil treatment presumably amplifies the guanylin response through GC-C. Guanylin secretion is stimulated by the ingestion of a salty meal, which prepares the gut for the osmotic imbalance. ${ }^{60,61}$ The present study suggests that guanylin might also serve to prepare the mucosal epithelium for an increase in redox stress arising from the metabolic stimulation of commensal bacteria by incoming nutrients.

Taken together, our results have identified FoxO3a as part of a novel endogenous antioxidant protection pathway in the luminal epithelium of the colon in both mice and humans. Activation of FoxO3a by PKG2 indicates that the cGMP signaling axis may have the important role of coupling antioxidant protection to diet-induced guanylin secretion in the colon. The association of ROS with colitis and colorectal cancer further suggests that FoxO3a activation by cGMP contributes to the protective effects of this pathway that are well documented in preclinical models for these diseases. Moreover, our demonstration that we can activate this pathway to reduce redox stress in the colon mucosa using PDE inhibitors further highlights the therapeutic potential of this class of drugs for treating intestinal disease.

\section{Supplemental Data}

Supplemental material for this article can be found at http://dx.doi.org/10.1016/j.ajpath.2016.10.016.

\section{References}

1. Marchiando AM, Graham WV, Turner JR: Epithelial barriers in homeostasis and disease. Annu Rev Pathol 2010, 5:119-144

2. Medema JP, Vermeulen L: Microenvironmental regulation of stem cells in intestinal homeostasis and cancer. Nature 2011, 474:318-326 
3. Simons BD, Clevers H: Stem cell self-renewal in intestinal crypt. Exp Cell Res 2011, 317:2719-2724

4. Hering NA, Fromm M, Schulzke JD: Determinants of colonic barrier function in inflammatory bowel disease and potential therapeutics. J Physiol 2012, 590:1035-1044

5. John LJ, Fromm M, Schulzke JD: Epithelial barriers in intestinal inflammation. Antioxid Redox Signal 2011, 15:1255-1270

6. McCole DF, Barrett KE: Epithelial transport and gut barrier function in colitis. Curr Opin Gastroenterol 2003, 19:578-582

7. Bhattacharyya A, Chattopadhyay R, Mitra S, Crowe SE: Oxidative stress: an essential factor in the pathogenesis of gastrointestinal mucosal diseases. Physiol Rev 2014, 94:329-354

8. Circu ML, Aw TY: Redox biology of the intestine. Free Radic Res 2011, 45:1245-1266

9. Huycke MM, Abrams V, Moore DR: Enterococcus faecalis produces extracellular superoxide and hydrogen peroxide that damages colonic epithelial cell DNA. Carcinogenesis 2002, 23:529-536

10. Jones RM, Mercante JW, Neish AS: Reactive oxygen production induced by the gut microbiota: pharmacotherapeutic implications. Curr Med Chem 2012, 19:1519-1529

11. Neish AS: Redox signaling mediated by the gut microbiota. Free Radic Res 2013, 47:950-957

12. Swanson PA 2nd, Kumar A, Samarin S, Vijay-Kumar M, Kundu K, Murthy N, Hansen J, Nusrat A, Neish AS: Enteric commensal bacteria potentiate epithelial restitution via reactive oxygen speciesmediated inactivation of focal adhesion kinase phosphatases. Proc Natl Acad Sci U S A 2011, 108:8803-8808

13. Forte LR Jr: Uroguanylin and guanylin peptides: pharmacology and experimental therapeutics. Pharmacol Ther 2004, 104:137-162

14. Steinbrecher KA, Cohen MB: Transmembrane guanylate cyclase in intestinal pathophysiology. Curr Opin Gastroenterol 2011, 27: $139-145$

15. Nakazato M: Guanylin family: new intestinal peptides regulating electrolyte and water homeostasis. J Gastroenterol 2001, 36:219-225

16. Li P, Lin JE, Chervoneva I, Schulz S, Waldman SA, Pitari GM: Homeostatic control of the crypt-villus axis by the bacterial enterotoxin receptor guanylyl cyclase $\mathrm{C}$ restricts the proliferating compartment in intestine. Am J Pathol 2007, 171:1847-1858

17. Steinbrecher KA, Wowk SA, Rudolph JA, Witte DP, Cohen MB: Targeted inactivation of the mouse guanylin gene results in altered dynamics of colonic epithelial proliferation. Am J Pathol 2002, 161: 2169-2178

18. Garin-Laflam MP, Steinbrecher KA, Rudolph JA, Mao J, Cohen MB: Activation of guanylate cyclase $\mathrm{C}$ signaling pathway protects intestinal epithelial cells from acute radiation-induced apoptosis. Am J Physiol Gastrointest Liver Physiol 2009, 296:G740-G749

19. Han X, Mann E, Gilbert S, Guan Y, Steinbrecher KA, Montrose MH, Cohen MB: Loss of guanylyl cyclase C (GCC) signaling leads to dysfunctional intestinal barrier. PLoS One 2011, 6:e16139

20. Harmel-Laws E, Mann EA, Cohen MB, Steinbrecher KA: Guanylate cyclase $\mathrm{C}$ deficiency causes severe inflammation in a murine model of spontaneous colitis. PLoS One 2013, 8:e79180

21. Lin JE, Snook AE, Li P, Stoecker BA, Kim GW, Magee MS, Garcia AV, Valentino MA, Hyslop T, Schulz S, Waldman SA: GUCY2C opposes systemic genotoxic tumorigenesis by regulating AKT-dependent intestinal barrier integrity. PLoS One 2012, 7:e31686

22. Li P, Schulz S, Bombonati A, Palazzo JP, Hyslop TM, Xu Y, Baran AA, Siracusa LD, Pitari GM, Waldman SA: Guanylyl cyclase $\mathrm{C}$ suppresses intestinal tumorigenesis by restricting proliferation and maintaining genomic integrity. Gastroenterology 2007, 133:599-607

23. Shailubhai K, Yu HH, Karunanandaa K, Wang JY, Eber SL, Wang Y, Joo NS, Kim HD, Miedema BW, Abbas SZ, Boddupalli SS, Currie MG, Forte LR: Uroguanylin treatment suppresses polyp formation in the $\operatorname{Apc}(\mathrm{Min} /+)$ mouse and induces apoptosis in human colon adenocarcinoma cells via cyclic GMP. Cancer Res 2000, 60: $5151-5157$
24. Markert T, Vaandrager AB, Gambaryan S, Pohler D, Hausler C, Walter U, De Jonge HR, Jarchau T, Lohmann SM: Endogenous expression of type II cGMP-dependent protein kinase mRNA and protein in rat intestine: implications for cystic fibrosis transmembrane conductance regulator. J Clin Invest 1995, 96:822-830

25. Pfeifer A, Aszodi A, Seidler U, Ruth P, Hofmann F, Fassler R: Intestinal secretory defects and dwarfism in mice lacking cGMPdependent protein kinase II. Science 1996, 274:2082-2086

26. Wang R, Kwon IK, Thangaraju M, Singh N, Liu K, Jay $P$, Hofmann F, Ganapathy V, Browning DD: Type 2 cGMP-dependent protein kinase regulates proliferation and differentiation in the colonic mucosa. Am J Physiol Gastrointest Liver Physiol 2012, 303: G209-G219

27. Wang R, Kwon IK, Singh N, Islam B, Liu K, Sridhar S, Hofmann F, Browning DD: Type 2 cGMP-dependent protein kinase regulates homeostasis by blocking c-Jun N-terminal kinase in the colon epithelium. Cell Death Differ 2014, 21:427-437

28. Eijkelenboom A, Burgering BM: FOXOs: signalling integrators for homeostasis maintenance. Nat Rev Mol Cell Biol 2013, 14:83-97

29. Lin JE, Li P, Snook AE, Schulz S, Dasgupta A, Hyslop TM, Gibbons AV, Marszlowicz G, Pitari GM, Waldman SA: The hormone receptor GUCY2C suppresses intestinal tumor formation by inhibiting AKT signaling. Gastroenterology 2010, 138:241-254

30. Burgering BM: A brief introduction to FOXOlogy. Oncogene 2008, $27: 2258-2262$

31. Fu Z, Tindall DJ: FOXOs, cancer and regulation of apoptosis. Oncogene 2008, 27:2312-2319

32. Tzivion G, Dobson M, Ramakrishnan G: FoxO transcription factors: regulation by AKT and 14-3-3 proteins. Biochim Biophys Acta 2011, 1813:1938-1945

33. Klotz LO, Sanchez-Ramos C, Prieto-Arroyo I, Urbanek P, Steinbrenner H, Monsalve M: Redox regulation of FoxO transcription factors. Redox Biol 2015, 6:51-72

34. Kops GJ, Dansen TB, Polderman PE, Saarloos I, Wirtz KW, Coffer PJ, Huang TT, Bos JL, Medema RH, Burgering BM: Forkhead transcription factor $\mathrm{FOXO} 3$ a protects quiescent cells from oxidative stress. Nature 2002, 419:316-321

35. Kwon IK, Wang R, Thangaraju M, Shuang H, Liu K, Dashwood R, Dulin N, Ganapathy V, Browning DD: PKG inhibits TCF signaling in colon cancer cells by blocking beta-catenin expression and activating FOXO4. Oncogene 2010, 9:3423-3434

36. Brunet A, Bonni A, Zigmond MJ, Lin MZ, Juo P, Hu LS, Anderson MJ, Arden KC, Blenis J, Greenberg ME: Akt promotes cell survival by phosphorylating and inhibiting a Forkhead transcription factor. Cell 1999, 96:857-868

37. Schneider CA, Rasband WS, Eliceiri KW: NIH Image to ImageJ: 25 years of image analysis. Nat Methods 2012, 9:671-675

38. Browning D, Kwon IK, Wang R: The cGMP-dependent protein kinases as potential targets for colon cancer prevention and treatment. Future Med Chem 2010, 2:15

39. Saha S, Chowdhury P, Pal A, Chakrabarti MK: Downregulation of human colon carcinoma cell (COLO-205) proliferation through PKGMAP kinase mediated signaling cascade by E. coli heat stable enterotoxin (STa), a potent anti-angiogenic and anti-metastatic molecule. J Appl Toxicol 2008, 28:475-483

40. Wu Y, Chen Y, Qu R, Lan T, Sang J: Type II cGMP-dependent protein kinase inhibits EGF-triggered signal transduction of the MAPK/ERK-mediated pathway in gastric cancer cells. Oncol Rep $2012,27: 553-558$

41. Kensler TW, Wakabayashi N, Biswal S: Cell survival responses to environmental stresses via the Keap1-Nrf2-ARE pathway. Annu Rev Pharmacol Toxicol 2007, 47:89-116

42. Jiang L, Chen Y, Li Y, Lan T, Wu M, Wang Y, Qian H: Type II cGMP-dependent protein kinase inhibits ligand induced activation of EGFR in gastric cancer cells. Mol Med Rep 2014, 9:1405-1409

43. Sang J, Chen Y, Jiang L, Tao Y, Wu Y, Wang Y, Li Y, Lan T, Shao G: Type II cGMP-dependent protein kinase inhibits 
ERK/JNK-mediated activation of transcription factors in gastric cancer cells. Mol Med Rep 2012, 6:1190-1194

44. Wu M, Chen Y, Jiang L, Li Y, Lan T, Wang Y, Qian H: Type II cGMP-dependent protein kinase inhibits epidermal growth factor-induced phosphatidylinositol-3-kinase/Akt signal transduction in gastric cancer cells. Oncol Lett 2013, 6:1723-1728

45. Saglam O, Garrett CR, Boulware D, Sayegh Z, Shibata D, Malafa M, Yeatman T, Cheng JQ, Sebti S, Coppola D: Activation of the serine/threonine protein kinase AKT during the progression of colorectal neoplasia. Clin Colorectal Cancer 2007, 6:652-656

46. Hoogeboom D, Essers MA, Polderman PE, Voets E, Smits LM, Burgering BM: Interaction of FOXO with beta-catenin inhibits betacatenin/T cell factor activity. J Biol Chem 2008, 283:9224-9230

47. Wang A, Keita $\AA$ V, Phan V, McKay CM, Schoultz I, Lee J, Murphy MP, Fernando M, Ronaghan N, Balce D, Yates R, Dicay M, Beck PL, MacNaughton WK, Söderholm JD, McKay DM: Targeting mitochondria-derived reactive oxygen species to reduce epithelial barrier dysfunction and colitis. Am J Pathol 2014, 184:2516-2527

48. Yang JY, Zong CS, Xia W, Yamaguchi H, Ding Q, Xie X, Lang JY, Lai CC, Chang CJ, Huang WC, Huang H, Kuo HP, Lee DF, Li LY, Lien $\mathrm{HC}$, Cheng $\mathrm{X}$, Chang KJ, Hsiao $\mathrm{CD}$, Tsai FJ, Tsai $\mathrm{CH}$, Sahin AA, Muller WJ, Mills GB, Yu D, Hortobagyi GN, Hung MC: ERK promotes tumorigenesis by inhibiting FOXO3a via MDM2mediated degradation. Nat Cell Biol 2008, 10:138-148

49. Sancho R, Nateri AS, de Vinuesa AG, Aguilera C, Nye E, SpencerDene B, Behrens A: JNK signalling modulates intestinal homeostasis and tumourigenesis in mice. EMBO J 2009, 28:1843-1854

50. Zhou W, Cao Q, Peng Y, Zhang QJ, Castrillon DH, DePinho RA, Liu ZP: FoxO4 inhibits NF-kappaB and protects mice against colonic injury and inflammation. Gastroenterology 2009, 137:1403-1414
51. Maiese K: FoxO proteins in the nervous system. Anal Cell Pathol (Amst) 2015, 2015:569392

52. Peng SL: Foxo in the immune system. Oncogene 2008, 27: 2337-2344

53. Stehr W, Mercer TI, Bernal NP, Erwin CR, Warner BW: Opposing roles for p21(waf1/cip1) and p27(kip1) in enterocyte differentiation, proliferation, and migration. Surgery 2005, 138:187-194

54. Tamura RE, de Vasconcellos JF, Sarkar D, Libermann TA, Fisher PB, Zerbini LF: GADD45 proteins: central players in tumorigenesis. Curr Mol Med 2012, 12:634-651

55. Roediger WE: Utilization of nutrients by isolated epithelial cells of the rat colon. Gastroenterology 1982, 83:424-429

56. Colgan SP, Taylor CT: Hypoxia: an alarm signal during intestinal inflammation. Nat Rev Gastroenterol Hepatol 2010, 7:281-287

57. Ferber EC, Peck B, Delpuech O, Bell GP, East P, Schulze A: FOXO3a regulates reactive oxygen metabolism by inhibiting mitochondrial gene expression. Cell Death Differ 2012, 19: 968-979

58. Peck B, Ferber EC, Schulze A: Antagonism between FOXO and MYC regulates cellular powerhouse. Front Oncol 2013, 3:96

59. Vaandrager AB, Bot AG, Ruth $\mathrm{P}$, Pfeifer A, Hofmann F, De Jonge HR: Differential role of cyclic GMP-dependent protein kinase II in ion transport in murine small intestine and colon. Gastroenterology 2000, 118:108-114

60. Sindic A, Schlatter E: Cellular effects of guanylin and uroguanylin. J Am Soc Nephrol 2006, 17:607-616

61. Steinbrecher KA, Rudolph JA, Luo G, Cohen MB: Coordinate upregulation of guanylin and uroguanylin expression by hypertonicity in HT29-18-N2 cells. Am J Physiol Cell Physiol 2002, 283: C1729-C1737 